JKAP (Jurnal Kebijakan dan Administrasi Publik)

Vol. 20 No 1 - May 2016, p84-94

p-ISSN 0852-9213, e-ISSN 2477-4693

Available Online at http://journal.ugm.ac.id/jkap

\title{
Implementation of Disaster and Risk Management Policy in the East-Cost of Madagascar
}

\author{
Rakotondrasoa Faramalala \\ Public Administration Department \\ Parahyangan Catholic University Bandung Indonesia \\ phaarra@yahoo.fr
}

Received: March 2016

Accepted: April 2016

Published: May 2016

\begin{abstract}
The implementation of Disaster and Risk Management (DRM) policy in Madagascar was a great success and an evolution from its birth until today thanks to these different stakeholders. This implementation that has helped a lot the improvement of living standards of the local population in eastern of Madagascar before, during and after the passage of an aleas (random and unpredictable event). Yet blocking factors even been known because the implementation is not fully satisfactory. This study aims to analyze the problems of implementation. Despite unceasing improvement, the local population still has a very low impact strength and after each cyclone crossing, the same situation returns. To improve this implementation, I will also suggest few solutions that could solve these problems, so that each level actors can improve their own policy and work method. Note that these solutions were made after long lived with the community.
\end{abstract}

Keywords: decentralization, disasters, hazards, implementation, management, risk, public policy 


\section{INTRODUCTION}

Implementation of public policy is the process of implementation of decisions. Implementation of talk can characterize a time of public action where the decision confronts reality through the implementation of government directives, here was a topic on the implemented policy public DRM in Madagascar. The original idea for this study comes from the statistical material losses and casualties which do not improve as it predicted in public policy. Since the year 1995 until 2005, including Madagascar did not yet know the practical mitigation strategy, the statistic does not surprise given that even the state does not mastered the reduction of vulnerability strategy. But from the year 2005, since the Hyogo Framework launched in 2010 that strictly requires the intervention of the state in mitigation and environmental impacts. An emergency evaluation at each cyclone passage was made and found that despite all the efforts made, the number of victims do not stop and do not improved: $70 \%$ ravaged houses, social infrastructure has $72 \%$ destroyed: schools, hospitals, road, rapid increase of diseases, agricultural infrastructure and agriculture $80 \%$ destroyed, casualties: 1500-2000 losses at each cyclone passage, and economic losses estimated up to 100 million US dollars per year. This means that the same situation is repeated at each cyclone passage. So that is why we speak in this study the problems on the implementation of public policy by speaking from the legislation adopted up to the real implementation. Yet we must not forget that despite the repetitive situation in case of cyclone or flood, it finds a consequent evolution on the preparation of the community face the passages of aleas (random or unpredictable event) thanks to the implementation of public policy because before, all the houses are totally destroyed or at least $95 \%$, social infrastructure completely destroyed. But what interests us here this is the reason for this slight improvement. The issues it what are the factors that block implementation. To better understand the subject we will divide into 2 parts, in the first part: the general presentation of public policy DRM and in the 2nd part of the implementation DRM public policy.

Theoritical Framework. The Top down approach to implementing is a system of command and control of the government in the project, which concerns the general basic population or the community directly concerned. The top down system has: (1) Coherent and clear goals but also articulated at the top of the hierarchy, goals in public policy are clear and formal with the Hyogo Framework. (2) Knowledge of the causes and relevant effects, analyzes were made even before public policy writing (3) a clear hierarchy of powers, in Madagascar, the Decentralization of the management of risk and disasters is one of the faces showing the hierarchization of the system. (4) Rules at the top and the policy is in line with the rules, the national office of risk and disaster management as well as the ministry of interior established the rules according to the regulation. (5) Resources / ability to run up. The top-down approach is rational global approach to planning. It is compatible with democracy in mind, then the elected delegate the authority to 
implement the non-elected officials (civil servants) who are accountable to the democratically elected representatives in the community. The employees of the national office and the employees of the Ministry of Interior are the nonelected. However, raise the most depressants can implement the policy with the standards that citizens do not understand, which could also bypass their rational preferences. When this happens, top-down is no longer implemented, but tactics.

The top-down perspective assumes that the objectives of the policy can be specified by decision and that the application can be completed successfully by setting up certain mechanisms (Palumbo and Calista 1990, p13). The essential point is that policymakers possess a strong capacity of implementers controller and all players. Van Meter and Van Horn (1975). The government has a large role to check the activities of NGOs which are the principals actors of the implementation in Madagascar .And Mazmanian and Sabatier (1978, p18): the implementation is related with the decision taken by the authorities in the public policy. Jeffrey Pressman and Aaron Wildavsky (1973) discuss the extent to which the successful implementation depends on the links between the various agencies and departments to local. This level that involves the community in the forefront of the responsibility. And this shows the necessity of fokontany of power and committee members who are elected democratically.

In all the top-down theory is based on the hierarchical level of power coming up at the community level, which is unquestionably with public policy and the implementation of risk management and disaster Madagascar.

\section{Top-down theory and repetition problems of the community after the passage of a cyclone}

Decentralization is one of the policies in the public policy DRM in Madagascar. This system has had great success and since it does not support the Top-Down theory that explains very clearly the prior analysis befire the writing of public policy but in particular the hierarchization. Yet this does not prevent the failures of this theory, because the problem is that there is always an alarming repetition of the problems after the passage of cyclone or inundation, the first step of this theory and also the 2nd stage plays the key role. These are: first, have a clear objective and coherent then knowledge relevant causes and effects. Despite the clear and coherent objectives raised by the Hyogo Framework, Madagascar must specify its own goals to make it more clear and Coherent because if the results are not satisfactory, it is in the consistency of public policy which knows a gap. This incoherence necessarily disrupts the goals that are also not very specific. In evoking the hierarchization; the lowest level cannot not jog to the highest level because of resources lack of. So have to prioritize in the first step of how this theory possesses the resources and skills. The lens does not realize perfectly without the cohesion and cohesion must consider the resources including the ability to achieve the goal.

For top-down theory that focuses on the role of policy makers in the control. What made 
fail failed the hierarchization or decentralization of DRM because yes the highest level (NodRm) only controller or too plays the role of controller which prevents a good cooperation and slowed all activities. That is why situations repeat themselves every year. That is why we also talk about role of NGOs because top-down theory according to Jeffrey Pressman and Aaron Wildavsky (1973) emphasizes the closer links between Ministers, organizations and the local community on the implementation and success the implementation of public policy.

In connection with the problems of implementation, we can say directly that an implementation may fail in this top-down theory of whether one of the pillars is not at the level to understand the objective. The talking of a few lowlevel studies of local committees of DRM.

The theory is the top-down theory key of the of public policy implementation in Madagascar. There are invaluable results despite the problems encountered. And hierarchization levels (decentralization), goals, causes the knowledge, relevant effects, rules, resources and Capacities play a very important role in achieving the objectives.

\section{RESEARCH METHODS}

All of this research study were made since the year 2012 within the local community, risk management and disaster committees in each level and interviews with officials of national office on DRM in Madagascar and with responsible within CARE international also. The research is divided into 2 parts: the experiences I even within CARE International and analysis of data.

\section{By experiences}

I will like to put clear from the beginning that my humanitarian work at Care International Madagascar has an incentive to do more research on DRM Madagascar, particularly on the effectiveness of public policy. Care International is an NGO that implement public policy DRM Madagascar.

The first step of the research was the participatory research method: to map resources, risk mapping, seasonal calendar, historical timeline, Venn diagram. This method has two major objectives: to involve the local community to analyze their situation, and take out the problems and threats faced by the community during the year. Much of this analysis was made with the SWOT method. Because it is the same community that suggests solutions to their problems after having presented the straights of their locality. This means solving the problems in using their own way. This working party has been out of the emergency preparation plans written by the same Committees themselves and assisted by assistants Social mobilization like me. After these analyzes, so we could know all the problems of the community before, during and after the hurricane and inundation. The solutions achievable within the community and the responsibilities of each committee member during the passage of a alea. Almost all towns and fokonta$n y$ in the eastern part of Madagascar were able to plan their preparation for emergencies. The number of established plan is around 200 in end 
of 2013, and these plans are updated annually by the same committees.

The method of participatory research demarches was based on the concept LCSM (Living Condition of Securization Menage: Household ability to respond to basic needs such as education, health, food and nutrition, housing, infrastructure and environment)

\section{Data and field visit analysis}

After the implementation of public policy, made by the state or NGOs, we could know the problems encountered. First data obtained demonstrate direct problem of public policy and the weakness of the State taking responsibility. The second type of analysis shows how target communities perceive public policy implementation.

The second type of data collected was in the DRM national office in Madagascar and within CARE International Madagascar has evoked their qualitative work on the implementation of this public policy.

\section{RESULTS AND DISCUSSIONS}

\section{A. OVERVIEW OF PUBLIC POLICY IN MADAGASCAR DRM}

\section{Origin of DRM in Madagascar}

\section{Why Decentralization of DRM it is so im-} portant and urgent priority for the state Compared to many others?

Madagascar is The Most country climate shocks exposed in Africa after-Comoros. The country is regularly affected by cyclones, floods and drought. It is estimated that almost quarter of the population (Approximately 5million people) live in risk areas. Madagascar is among the top 10 countries with the highest index of mortality risks associated with cyclones. The country is between medium risk and high risk (6 Index), with an average of 30-100 deaths per year, Slightly lower than that of Bangladesh (Class 8), of the Philippines, with a goal similar risk level to that of India, the Dominican Republic and Haiti. Madagascar is an island at risk in matters of natural disasters especially flooding and cyclone. Madagascar's east coast is classified as 2nd red area in the Indian Ocean (cyclone: each year, 7 to 12 cyclones spend months from October up to April). Cyclones are a constant threat to the people living on the coast of Madagascar. For example, the 2008 hurricane season, the damage is estimated at $\$ 176$ million, affected 535,000 peoples, causing 106 deaths, damaging $4 \%$ of schools, $6 \%$ of basic health centers, and 1.1 million hectares of rice fields. In 1994, cyclone Geralda: 400 dead and 40000 persons displaced

\section{Decentralization of DRM Madagascar}

Law No. 2003 - 010 of 5 September 2003 national policy is about Disaster and Risk Management (DRM): firstly, determine the national policy of DRM; secondly, general provisions: it provides the mechanisms and measures to ensure, in any status of risk and disasters, whatever their nature, origin and importance of the service requirements necessaries of life of the population and Its defense. Thirdly, the implementation: they define the guidelines and priority devices to follow in terms of risk management and disaster 
in the short, medium or long term. Fifth, structure: an instance of design and supervision including elected parliamentarians: an instance of management, coordination, monitoring and supporting of programs and actions. Sixth, financing mechanisms: annual finance laws establish financial mechanisms to manage financial Risks and disasters based on the need in including national level: a budget allocation for prevention and mitigation; a contingency fund; a budget allocation for rehabilitation and reconstruction. And finally, the final provisions. It is the laws that are consistent public policies in the decentralization of DRM.

\section{a. STRUCTURE}

Decentralization logically following the decentralization of the administrative structure; That is to say the central state to the regions to the district to the municipality up to fokontany. In each level, there is a committee, a committee that includes subcommittees. The regions, districts, municipalities and fokontany heads of the committee are automatically leader of the committee in the respective levels. This represents a total commitment of leaders. The committee's members are elected by the local community, it also engaged the population, and on failure of the committee or the committee member, they can change by a simple verbal process. The number of committees depends on a fokontany by another because it depends on the number of population or community volunteering, but in general from 6 up to 25 members.

The highest level of the committee has the right to monitor the lower level and has a duty to monitor. Normally, following the constitution, there are one (1) national office of DRM, 22 regional comities of DRM (RCDRM), 119 district comities of DRM (DCDRM) 1557 communal comity of DRM (CCDRM) and local 17500 comities of DRM (LCDRM).

\section{b. GOALS}

Empower the area, district and commune. Improve coordination between area, district, town and community. Make easier and faster the emergency activities. Reduce the vulnerability of the population (by themselves). Increase the resilience rate of population (by themselves).

\section{Actors implemented DRM public policy in Madagascar}

State. As a designer of public policy, the state should be one of the actors of implementation. Even if the state does not fully participle in implemented public policy, it has the duty to check NGOs while NGOs follow the plan performs. Consult NGOs on the problems encountered on implementation step, but especially revise public policy with these other actors.

NGOs. NGOs have a very important role in the implementation of public policy of DRM in Madagascar, because the state lacks financial means, then the NGOs work for public policy is executed as it is written. The main NGO actors in DRM Madagascar are: CRS (Catholic Relief Service), United Nations services as WFP (World Food Program), FAO, CARE, and the divers associations such as the 
Red Cross. During the past 15 years, these NGOs were the first rescuers after passing aleas in Madagascar but above the cyclone passage. Approximately $85 \%$ of the economic, social losses are restored by these NGOs. Before, for example in 1990, these NGOs do not yet occupied the situation before alea passage :prevention and mitigation, one of the two phases of the DRM. A few years later, with the decentralization of public policy on DRM, Madagascar was forced to adopt new policy requiring the reduction of the vulnerability of the population, the key is to success in the disaster and risk reduction (DRR). This phase of the DRR is fully occupied by NGOs because this phase requires much more financial and material but also human. These NGOs share territories prior to settle for good organizing work in each region.

Community. We saw above that the community is one of the actresses on DRM in Madagascar, it is the victim of disasters. Yet we do not let just remain as a victim but has to fight against these disasters, while increasing levels of resilience and decreasing vulnerability. The community is the first responsible of their daily lives. By intermediary of these NGOs, the community is invited to an analysis by itself to provide a better solution to its situation. So the community is one of the players in the implementation of the DRM public policy in Madagascar.

\section{B. IMPLEMENTION OF DRM POLICY IN} MADAGASCAR

\section{Problems of Implementation}

a. Money
Throughout the area in Madagascar, the financial resources still pose problems. Yet the state test to look for funding, on the inside (for the ministerial budget) and outside (through the intermediary services of the United Nations and other donors). Despite everything, the money is still not enough to implement public policy.

Since the global economic crisis, many donors have closed their wallet or at least have a lower half their financial support to poor countries as many African states including Madagascar. Rich countries like the US have reduced their funding and have changed their method of financing, requires more maturity on demand, more control and monitoring in the implementation. Was facing such consequences which result is evident in the implementing of public policy. Funding is reduced to half, possible work also reduced.

We must not forget that even installing DRM Decentralization in Madagascar; the budget is still centralized in the center; is that there has inefficiency and fiscal imbalance ministerial: $95 \%$ for the ministry, $1,5 \%$ for the regions, and $3,5 \%$ for the municipalities. So the regions budgets are very low then it is from the level of the region that has so much work to do.

\section{b. Study Level of the Community Low}

By realizing public policy, there are some remarks as the level of study of the community in the perception of public policy that affects implementation. During the connection with the community through training or local infrastructure installation, the employees of the NGO 
notes that it is very difficult to explain to the community the risk of their daily activities; it is very difficult to make out an analysis of a community by itself. All this because of their rather low level of study. Therefore, it takes more time than expected, and also more material means to make more easy the understanding of the committees.

During the Decentralization of DRM, a difficulty as there is on the right people sought to form committees. Because the committees required someone skills more than others and have a minimum capacity to be able transferring information to the basic community; which is really very difficult for fokontany that are far from the city. Some 20 members of committees that possess 2 to 5 peoples who can read and write, and this has a serious impact on the issuance, the collection of all information in the DRM or the information play a very important role in the DRM. And this leads up to miscommunication because there is poor understanding.

Lack of municipal budget; although the municipality has made efforts on the budget for the DRM, the budget is still not enough. Lack of national budget; the national budget is Insufficient, so the state always call to international aid. The bulk of the work is done by NGOs. despite the decentralization of DRM Madagascar, some area do not-have yet committees regional, municipal or district while because lack of budget and because the state does not find these areas as priority areas

Certain regions (coastal areas) do not-have the preparation plan for emergency because there's no NGOs while the state cannot do nothing because financial default, we cannot forget that big share of financial resources to execute all activities are from external aids. Favoritism reign since decentralization in the community in an emergency situation. The committees tend to favor their families when there is distribution of aid for victims and homeless. Often this leads to social conflict

\section{c. Public Policy}

The 3rd problem arises on the same public policy, public policy is not yet specified, that is to say, it is too general and focuses only on the vagaries frequent as the flood and cyclone, while there are also aleas that the state neglected its existence as drought or locust invasion. In an emergency, the implementation often encounter this problem because of generalization of any public policy in DRM. Much does not correspond to the real situation; take as an example the cyclone crossing in southern of Madagascar and the east. In the east after, the cyclone passage about 2 weeks after that period, there is still strong rain precipitation, instead, in the south which represents a very dry climate, after a cyclone passing, time become very dry. The risk is very different, and disasters also. Yet, in the content of public policy, relief after cyclone passage is the same while it should be different because an aunt or plastic shitting are not necessary in the south because it is very hot and there is no rain, they only serve them in canoes sail. Having said that it is necessary to differentiate public policies even in a single domain. 
2. The Role of NGOs in the Implemented DRM Public Policy

By Jeffrey Pressman and Aaron Wildavsky (1973), the link between implementing agency, ministry and the local community is very important in the success of the public policy implementation and because we already talked at length about the ministry or NodRm, so we'll start talking NGOs implementation as first implementer

NGOs play an important role in implementation than the state. First, it is the NGOs that have set up and execute the Decentralization of DRM in Madagascar (vangaindrano, Vatomandry, Brickaville, Fenerive-Est, Toamasina) The regionals committees, district committees, and communal committees, locales committees were installed by CARE NGO: around 60 LCDRM and with more than thousand members on one project called Soa Fiarina. After this installation, it is the NGO that also strengthen the capacity of each committee level. This analysis focuses mainly the field of DRM committees to make known what is the risk and disaster management, all necessary definitions. But above all teach how to defend the increasing rate of disasters, increase resilience. Through the intermediary of NGOs, $80 \%$ members of each of the committees have received full training to make an analysis of their situation before writing the emergency plan (for the same community). The emergency plan helps the community to memorize all necessary activities before, during and after the hurricane. This plan is not only useful for memories these activities but also engages the community to exe- cute together all that is written in this plan.

NGOs do not react just before the arrival of aleas (eg cyclone), they are there and ready when the vagaries arriving despite the fact that the community should know all necessary precautions to deal with the vagaries, there are always the victims and first arrived on seats are NGOs. They are for first aid: health (cure diseases), nutrition (food distribution to the homeless, ...), housing (to the homeless a place on: common aunt, ...); after first aid, they begin the rehabilitations of destroyed infrastructure: road, school, hospital, administrative office, rice fields, dam through the intermediary of VCT or ACT money against live or food against work ... benefiting more than 32,000 people in the districts of Brickaville and Vatomandory, the most severely affected areas of cyclone Giovanna in 2012, . Even if the aids which have been made by NGOs are not sufficient for the population, at least this much allege food security problem or others present on the shoulders of the community for at least one year.

In Madagascar, NGOs, before settling divides the scene of jobs. Some prefer to work in the west, certain want in East, or others working in the South West, it depends on each NGO. But the most interesting region for NGOs are the eastern part of Madagascar because the vagaries are more frequent and striking, yet even in the extreme south which is often hit by famine because of drought. Some people have trouble finding room, and NGOs and associations are the first came to rescue the victims before the arrival of the state. 


\section{Influence of NGOs (Care International}

Case) in Public Policy and the Implementation of DRM

As we saw above, the NGO has an important place within the implementation of public policy. Here we take the case of the NGO CARE INTERNATIONAL installed in Madagascar since 22 years. The influence of NGOs has also an important place in the community and the state. Because NGOs are much more influential within the community in relation to the state. Care is an NGO that works usually live in the management of risk and disasters. There are two programs within CARE: the emergency program and development program. The emergency program is implemented only after the passage of randomness, particularly a cyclone or inundation. The development program focuses on the long-term work that lasts at least 2 years but still focus in DRR.CARE is an international NGO very strong and well reputed in Madagascar, it works with several donors and recognized by its strong continuity of work. It is also an NGO that implements the DRM policy in Madagascar. One can even say that it is with the NGO CARE that all DRM committees of eastern Madagascar was able to establish their contingency plan: more than 60 contingency plans established. As we know from above, the DRM Committees are experiencing great difficulty in financial term to realize the activities set forth in their successive plan. Because and some NGOs like CARE can influence the state to revise the public policy of the true situation, or advocacy within the state to empower those committees. If we take for exam- ple the financial problem in the local or municipal committee: after the vulnerability scans with the community; having realized that the lack of financial means was one of the major obstacles to the realization of the contingency plan; after taking the decision with the community on the solution of these problems, the project manager on behalf of the community wrote a request to the authorities to give those committees so that they can make economic activities to strengthen their financial resources. This helps a lot the committees, because without money nothing they can while they cannot get money without the agreement of successive Authorities. Advocacy is one way of CARE and other NGOs to improve public policy and implementation as well.

\section{Solutions proposed facing problems}

The Stakeholders in the implementation must allow committees to do the activities that improve their financial resources to facilitate the realization of each activity enunciated in the plane of emergencies preparation. The state on the other side must improve the funding application system, recruit new employees who are specialists in financing request and have already experienced successes in financing demand in other organisms. Yet we must always strengthen the control over the management of these donations, whether in NGOs or at NODRM. Transparency is one of the weapons that the system has needs.

Set up the Decentralization DRM throughout Madagascar, but not only in the eastern areas, because all regions in Madagascar are at risk 
because Madagascar is an island.

Saw the Baseness of committees' educational level installed by the Decentralization DRM requires that the state and responsible NGOs reinforce the number of simulation exercises. This allows the local community to understand the role of each in time intemperate. If the members of committees cannot ensure $100 \%$ transfer message to the community, the simulation exercise is one of the most feasible and cost effective solutions. Increase or create for fokontany who have never practiced this system. It also is possible to increase the brackets used during all training and preparations, people who can neither read nor write are more flexible with the images. This means that the budget on the supports of material have to increase.

We must not forget that even if a type of aleas happens in two or three regions east of Madagascar, the consequences are not necessarily the same. Scientifically, it should be different, so the preparations should be different too. Stakeholders must put in place since the beginning of the hurricane season all possible alternatives to avoid surprises and bad results: to prepare for the effects of wind and inundation but not only winds.

\section{CONCLUSION}

To conclude, we can say that the implemented DRM public policy in Madagascar met with several problems in the financial sector is the most dominant. And this financial problem can lead to several other problems like communication, material or human. But we can also say that the adaptation of public policy at the community level is very difficult. Yet regarding the implemented DRM has seen more success than failure for regions that were already decentralized.

\section{REFERENCES}

Decentralisation a Madagascar, 2010, 20p

Law 2003 - 010 On 5 September 2003 On national policy Desaster and Risk Management in Madagascar

Mazmanian, D.A. and Sabatier, P.A. (1983), Implementation and Public Policy. Glenview, III.: Scott, Foresman

Plan de contingence national cyclones et inondations; Ministry of Interior; National office of Risks and disasters Management, Madagascar,2012,48p 